\title{
Correlation between Self-Efficacy with Activity of Daily Living on Post-Stroke Patients in TMS Clinic RSUD Dr. R. Koesma of Tuban
}

\author{
Noer Innayah ${ }^{*}$, Endah Nurul Kumarijati, Hanim Nur Faizah \\ Sekolah Tinggi Ilmu Kesehatan Nahdlatul Ulama, Tuban, Indonesia \\ pujoinnayah@gmail.com \\ ${ }^{*}$ Corresponding author
}

\section{Keywords:}

Self-Efficacy, ADL, Post-

Stroke Patients

\begin{abstract}
The Activity of Daily Living (ADL) is important for post-stroke patients. The study aims to identify the correlation of Selfefficacy with ADL on post-stroke patients in TMS Clinic Dr. R. Koesma Hospital of Tuban. Correlative analytic research design with a cross-sectional time approach. The study took a sample of 34 respondents by using Simple Random Sampling. Instrument research used questionnaires. Statistical tests used Spearman Rank. The dependent variable of the study is ADL and the independent variable self-efficacy. The results of the study found that ADL respondents were highly dependent $17.7 \%$ were found in respondents with low self-efficacy, independent $A D L 23.5 \%$ were obtained in respondents with moderate self-efficacy. Data analysis used the Spearman Rank with the significance of $\alpha=0.05$. Statistical test results $p=$ $0.03<\alpha=0.05$ showed there is a correlation between selfefficacy with ADL of patients after stroke. The role of nurses in improving self-efficacy by motivating and providing health education about $A D L$.
\end{abstract}

\section{INTRODUCTION}

Stroke is a serious neurology emergency ranked high as a cause of death. WHO defines stroke as a clinical sign that develops rapidly due to brain disorders focal (or global) with symptoms that last for 24 hours or more and can cause death without any other obvious cause besides vascular. stroke sufferers generally experience problems with fulfilling the activity of daily living (ADL) after stroke because of the limitations they experience. data from the medical record of RSUD Dr. R Koesma Tuban in December 2018 out of 64 stroke cases as many as 25 patients were in total dependence, 26 were partially dependent patients, 13 were patients with minimum dependency.

This will have an impact on declining levels of productivity and can lead to disruption of family socioeconomic (Dourman, 2013). Because patients with post-stroke mostly experience weakness in their motor skills causing them to experience decreased ability to do self-care, so they will need help from family or others to meet their needs.

The number of stroke patients in Indonesia based on the 2010 Population and Demographics Census (SKDI) in 2010 was 3,600,000 annually with a prevalence of 8.3 per 1000 population. The highest prevalence of stroke based on the diagnosis of health workers and symptoms was found in South 
Sulawesi (17.9\%), DI Yogyakarta (16.9\%), Central Sulawesi (16.6\%), followed by East Java at 16 per mile. An increase in stroke prevalence based on interviews (based on respondents' answers that have been diagnosed with health) and symptoms also increased from 8.3 per 1,000 in 2007 to 12.1 per 1,000 in 2013 (Riskesdas, 2013). In Tuban, the number of stroke sufferers has increased from year to year, this is based on data from the RSUD Dr. Koesma Tuban medical record. In 2017 the number of strokes in RSUD Dr. R Koesma numbered 574 cases, while in 2018 it rose to 862.

Post-stroke can be said to be the most difficult period for post-stroke sufferers, they will experience disabilities and the inability to carry out activities as before. One of them is the inability to do daily activities (ADL).

ADL is a person's independence in the activities of eating, bathing, dressing, dressing up, defecating, urinating, using the toilet, transferring mobility, and going up and downstairs. Based on research conducted by Morone ADL that can recover immediately after a stroke is the ability to defecate and small, while the low ability to recover rates are showering, dressing, dressing up, and climbing stairs (Morone, Paolucci, \& Iosa, 2015). The independence of stroke patients in meeting ADL is influenced by many factors that are grouped into external and internal factors. External factors include family support, availability of health facilities or facilities, and socioeconomic capabilities. While internal factors include age, stroke severity, and self-efficacy.

Factors that affect ADL according to the Middle Range in Theory Off Chronic Illness include (1) Experience. (2) Events that have been experienced with a bad event will decrease the level of activity of a person. (3) Skills, a capability, and capacity gained through deliberate effort, systematic and sustainable to smoothly and adaptively carryout complex activities or work functions that involve cognitive and technical skills. (4) Culture, a way of life that develops and is shared for a group of people and is passed down from generation to generation. (5) Confidence/Self Confidence, believing in the ability and self-assessment in carrying out tasks and choosing an effective approach. Divided into 2, namely: (1) Self Esteem, the overall view of the individual towards himself. (2) Self-efficacy, individual belief in the ability to be able to do something successfully. (6) Negative/bad habits will affect someone experiencing deterioration both physically and mentally. While good habits can be used to cure bad habits. (7) Cognitive function is the ability of attention, motivation, memory, consideration of problem-solving, and executive abilities such as planning, assessing, evaluating (Strub et al). (8) Support from Others, Giving support, motivation or enthusiasm and advice to others who are in a decision-making situation (Chaplin, 2006). (9) Health Access/Health Services, with close health access, can maintain and improve health, prevent and cure illnesses, and restore health.

Self-efficacy is an individual's belief that he can do something in a certain situation successfully. Based on the theory of self-efficacy put forward by Bandura, a person with low self-efficacy tends to have no confidence and tend to doubt their abilities. Self-efficacy in stroke patients includes selfconfidence in terms of functional status and self-management.

Factors Affecting Self-efficacy. Four factors affect self-efficacy, these four factors are also a source of self-efficacy: (1) Mastery Experience Everyone has mastery experience. This happens when someone tries to do something and is successful, so it can be said he has mastered something. (2) Vicarious Experience is someone's observation of the success or failure of others or models that have similarities with him. (3) Verbal Persuasion/Social Persuasion when someone gets verbal influence that he can achieve or master a task, he will be more likely to do the task. Someone else who verbally supports the achievement or mastery of the task will make someone have more confidence in himself. (4) Verbal Persuasion/Social Persuasion when someone gets verbal influence that he can achieve or master a task, he will be more likely to do the task. 


\section{METHOD}

The design of this study used a correlative analytic and cross-sectional approach. Correlative research is used to examine the relationship between variables (Hidayat, 2008) which is a study in which the independent variable of this study was self-efficacy and the dependent variable was ADL which is observed at the same time. The population in this study was 36 people. The size of the study sample was 34 respondents. The type of sampling in this study used simple random sampling.

Data were analyzed using the Spearman Rank statistical test with significance $\alpha=0.05$, with the help of SPSS if it was found $\rho<\alpha$, then H0 was rejected, meaning that there was a correlation between self-efficacy with ADL on post-stroke patients in the TMS Clinic, Dr. R Koesma Hospital of Tuban.

\section{RESULTS AND DISCUSSION}

\section{Results}

1. General Data

a. Characteristics of respondents based on age

Table 1

Distribution of Age Frequencies in Post-Stroke Patients

\begin{tabular}{cccc}
\hline No. & Age (Year) & Frequencies & Percentage (\%) \\
\hline 1. & $\begin{array}{c}\text { Late Adult } \\
(60-65)\end{array}$ & 11 & 32.4 \\
2. & $\begin{array}{c}\text { Intermediate Adult } \\
(41-60)\end{array}$ & 22 & 64.7 \\
3. & $\begin{array}{c}\text { Early adulthood } \\
(18-40)\end{array}$ & 1 & 2.8 \\
\hline & Total & 34 & 100 \\
\hline
\end{tabular}

The data in Table 1 showed that of the 34 respondents there was a majority (64.7\%) of middle adulthood (41-60 years).

b. Characteristics of respondents based on stroke duration

Table 2

Distribution of Duration of Treatment in Post-Stroke Patients

\begin{tabular}{cccc}
\hline No. & Stroke time & Frequencies & Percentage $(\boldsymbol{\%})$ \\
\hline 1. & $>1$ year & 3 & 8.8 \\
2. & $<1$ year & 31 & 91.2 \\
\hline & Total & $\mathbf{3 4}$ & $\mathbf{1 0 0}$ \\
\hline
\end{tabular}

The data in Table 2 showed the results that from 34 respondents there were almost all (91.2\%) with long periods of stroke $<1$ year.

c. Characteristics of respondents by sex

Table 3

Distribution of Gender Frequency in Post-Stroke Patients

\begin{tabular}{cccc}
\hline No. & Gender & Frequencies & Percentage (\%) \\
\hline 1. & Male & 23 & 67,6 \\
2. & Women & 11 & 32,4 \\
\hline \multicolumn{2}{c}{ Total } & $\mathbf{3 4}$ & $\mathbf{1 0 0}$ \\
\hline
\end{tabular}


The data in Table 3 showed the results that out of 34 respondents, most (67.6\%) were male respondents.

d. Characteristics of Respondents Based on Education

Table 4

Distribution of education frequency in post-stroke patients

\begin{tabular}{clcc} 
No. & Education & Frequencies & Percentage $(\boldsymbol{\%})$ \\
\hline 1. & SD & 7 & 20,5 \\
2. & SMP & 9 & 26,4 \\
3. & SMA & 13 & 38,4 \\
4. & D3 & 2 & 5,9 \\
5. & Bachelor & 3 & 8,8 \\
\hline & Total & $\mathbf{3 4}$ & $\mathbf{1 0 0}$ \\
\hline
\end{tabular}

The data in Table 4 showed the results that out of 34 respondents there were almost half $(38.4 \%)$ of respondents having a high school education.

e. Characteristics of Respondents Based on Marital Status

Table 5

Frequency Distribution of Marital Status in Post-Stroke Patients

\begin{tabular}{cccc}
\hline No. & Marital Status & Frequencies & Percentage (\%) \\
\hline 1. & Married & 32 & 94,2 \\
2. & single & - & - \\
3. & Widower widow & 2 & 5,8 \\
\hline Total & & $\mathbf{3 4}$ & $\mathbf{1 0 0}$ \\
\hline
\end{tabular}

The data in Table 5 showed the results that out of 34 respondents there was a majority (94.2\%) were respondents with marital status.

2. Special Data

a. Self-efficacy

Table 6

Frequency Distribution of Self-efficacy in Post-Stroke Patients

\begin{tabular}{cccc}
\hline No. & Self-efficacy & Frequencies & Percentage (\%) \\
\hline 1. & Self-efficacy high & 25 & 73,5 \\
2. & Self-efficacy medium & 8 & 23,6 \\
3. & Self-efficacy low & 1 & 2,9 \\
\hline Total & & $\mathbf{3 4}$ & $\mathbf{1 0 0}$ \\
\hline
\end{tabular}

The data in Table 6 showed that of the 34 respondents most (73.5\%) had good self-efficacy.

b. ADL

Table 7

Distribution of ADL Frequencies in Post-Stroke Patients

\begin{tabular}{clcc}
\hline No. & \multicolumn{1}{c}{ ADL } & Frequencies & Percentage (\%) \\
\hline 1. & Total Dependency & - & - \\
2. & Very dependent & 6 & 17.7 \\
3. & Partially Dependent & 1 & 3.0 \\
4. & Minimal Assistance & 19 & 55.8 \\
5. & Independent & 8 & 23.5 \\
\hline Total & $\mathbf{3 4}$ & $\mathbf{1 0 0}$ \\
\hline
\end{tabular}


The data in Table 7 showed that of 34 respondents there were half of ADL (55.8\%) still need minimal assistance.

3. Correlation between self-efficacy with ADL in post-stroke patients

Table 8

ADL Cross-Table According to Self-Efficacy in Post-Stroke Patients

\begin{tabular}{lcccccc}
\hline \multirow{2}{*}{$\begin{array}{c}\text { Self- } \\
\text { efficacy }\end{array}$} & \multicolumn{5}{c}{ ADL } & \\
\cline { 2 - 6 } & Independent & $\begin{array}{c}\text { Minimal } \\
\text { Assistance }\end{array}$ & $\begin{array}{c}\text { Partially } \\
\text { Dependent }\end{array}$ & $\begin{array}{c}\text { Very } \\
\text { Dependent }\end{array}$ & $\begin{array}{c}\text { Total } \\
\text { Dependency }\end{array}$ & \multirow{2}{*}{ Total } \\
\cline { 2 - 6 } & $\mathbf{N}(\%)$ & $\mathbf{N}(\%)$ & $\mathbf{N}(\%)$ & $\mathbf{N}(\%)$ & $\mathbf{N}(\%)$ & \\
\hline High & $5(20)$ & $16(64 \%)$ & $1(4 \%)$ & $3(12)$ & 0 & $25(100)$ \\
Medium & $3(37.5)$ & $3(37.5 \%)$ & 0 & $2(25)$ & 0 & $8(100)$ \\
Low & 0 & 0 & 0 & $1(100)$ & 0 & $1(100)$ \\
\hline \multicolumn{1}{c}{ Total } & $\mathbf{8 ( 2 3 . 5 )}$ & $\mathbf{1 9}(\mathbf{5 5 . 9})$ & $\mathbf{1 ( 2 . 9 )}$ & $\mathbf{6 ( 1 7 . 7 )}$ & $\mathbf{0}$ & $\mathbf{3 4}(\mathbf{1 0 0})$ \\
\hline
\end{tabular}

The data in Table 8 showed that of the 34 respondents, respondents with highly dependent ADL $(17.7 \%)$ were mostly obtained from respondents with low self-efficacy, whereas respondents with independent ADL (23.5\%) were more likely to get in respondents with moderate self-efficacy.

The analysis used in this study SPSS for windows with the Spearman Rank test with significance level $\alpha=0.05$ results obtained $p=0.038$ where the value of $p<0.05$, the correlation coefficient level of 0.357 , it can be concluded that $\mathrm{H} 1$ is accepted, meaning that there is a correlation between Selfefficacy with Activity Day Living in post-stroke patients at TMS Clinic Dr. R Koesma Hospital of Tuban.

\section{Discussion}

1. Self-efficacy in post-stroke patients at the TMS Clinic RSUD Dr. R. Koesma of Tuban

The results of data analysis and interpretation by the researchers that of the 34 respondents there were most (73.5\%) had good self-efficacy. Based on our data at the TMS Clinic Dr. R Koesma of Tuban Hospital, it was found that patients with high self-efficacy were found in patients with early adulthood and middle adulthood, while low self-efficacy was found in patients with late adulthood, whereas patients with a treatment duration of more than 1 year have high self-efficacy for low self-efficacy obtained in patients with a treatment duration of less than 1 year. High self-efficacy was obtained in patients with female sex that is equal to $76.9 \%$ while low self-efficacy was obtained in male patients by $4.8 \%$. In the cross table between marital status according to self-efficacy found in married patients higher self-efficacy compared with patients with widower status, low self-efficacy was obtained in widower patients with a percentage of $50 \%$, while for the cross table between levels of education according to self-efficacy it was found that high self-efficacy patients were obtained at patients with a diploma and bachelor education level of $100 \%$.

Social cognitive theory, low Self-efficacy can cause increased anxiety and avoidance behavior. Individuals will avoid activities that can aggravate the situation, this is not caused by threats but because they feel they cannot manage aspects at risk. People who have high Self-efficacy will have low-stress levels, and conversely, people who have low Self-efficacy will have high-stress levels, these individuals will easily experience distress and frustration.

There are four psychological mechanisms associated with self-efficacy and behaviors that appear according to Turk \& Okifuii (2002), namely:

1) Self-efficacy is considered to reduce anxiety along with physiological stimulation.

2) Someone with high self-efficacy will be able to distract their attention from a threatening physiological sensation.

3) Someone with adequate self-efficacy feels distressed on the physical sensation but tries to deal with it 
4) Physical sensations that are ignored or cause distress, individuals can make sense by changing their interpretations

In an activity that involves strength and stamina, a person will experience fatigue and pain, in this case, will also be related to physiological conditions and moods, there are four ways to change Selfefficacy According to Bandura (1997) and Rustika (2012), that is:

1) Improve body condition.

2) Reduces stress.

3) change negative emotions.

4) Correct misinterpretation of the state of the body

Wantiyah theory (2010) along with the development of adulthood, the increasing number of stressor level problems can affect an individual's self-efficacy (Ismatika \& Soleha, 2018). At the TMS clinic of RSUD Dr. R Koesma of Tuban, we found that most of the high self-efficacy was found in patients with middle adulthood and early adulthood. From these data it can be said that they are still trying to seek treatment and have a high desire to recover quickly and rise to be able to reactivate again, can immediately work, and return to socializing with friends and the surrounding community.

2. ADL in post-stroke patients at the TMS Clinic RSUD Dr. R Koesma of Tuban

Based on Table 7 showed that of the 34 respondents there were half $(55.8 \%)$ requiring minimal assistance. The data we obtained after researching the TMS Clinic Dr. R. Koesma Hospital of Tuban, for independent ADL, were mostly obtained in patients with moderate to late adulthood. patients with middle adulthood criteria were found to be ADL with a minimum of $54.5 \%$ assistance. From the cross table between the duration of treatment according to ADL, many independent ADLs are found in patients with a treatment duration of more than 1 year, while based on sex with ADL independently found in many men and vice versa ADL that is highly dependent is found in women. From the marital status of the data we get ADL independently there are many found in the marital status of marriage while patients are widower marital status found ADL is very dependent on the percentage of $100 \%$. The level of education also influences the independence of ADL, the data we get that many independent ADLs are obtained in patients with a Bachelor's level of education. ADL is highly dependent on getting in patients with junior high school graduates.

ADL behavior is influenced by experience and skills, motivation, beliefs, and cultural values, confidence (beliefs), habits, functional and cognitive abilities, social support, and facilities According to Riegel, Barbara (2012) in Middle Range theory. Based on Table 2 showed that of the 34 respondents there were almost all $(91.2 \%)$ of the duration of therapy experience in post-stroke patients is less than one year, it can influence ADL behavioral skills in daily life to maintain and improve their health status.

3. Correlation of self-efficacy with ADL in post-stroke patients in TMS Clinic RSUD Dr. R. Koesma of Tuban

The results of data analysis, respondents with highly dependent ADL (17.7\%) were mostly found in respondents with low self-efficacy, whereas respondents with independent ADL (23.5\%) were more likely to get respondents with moderate self-efficacy. From our research at the TMS clinic Dr. R Koesma Hospital of Tuban, it was found that ADL that was highly dependent was found in patients with widower marital status and also had low self-efficacy. Self-efficacy can be influenced by others or by verbal persuasion. The factor that influences ADL level according to Middle Range in Theory of Chronic Illness is support from others.

According to Prestiana and Purbandini (2012), someone who has high self-efficacy believes that they will be able to cope with events and situations effectively. High self-efficacy decreases fear of failure, increases aspiration, improves problem-solving, and analytical thinking ability. According to Bandura, 


\section{IJ-MDS International Journal of Multi Discipline Science (IJ-MDS)}

Vol. 2 No. 2 (2019)

e-ISSN: 2615-1707. Page: 85-91

people who have high self-efficacy will have higher morale in carrying out certain tasks compared to people who have low self-efficacy.

Post-stroke patients who experience motor weakness will try to manage and control by doing ADL to maintain and improve their health status. ADL independently will be a task for post-stroke patients both those who are and after getting therapy or when at home so that patients will always pay attention to ADL in their daily lives.

\section{CONCLUSION AND SUGGESTION}

\section{Conclusion}

There was a correlation with the low correlation coefficient between self-efficacy and activity day living on post-stroke patients in TMS Clinic Dr. R. Koesma Hospital of Tuban with $p$-value $=0.038<$ 0.05 .

\section{Suggestion}

Self-efficacy in the form of motivation or support from nurses can be used as a reference to increase ADL on post-stroke patients in TMS clinic Dr. R. Koesma Hospital of Tuban.

\section{REFERENCES}

Bandura A. (1997). Self-Efficacy: The Exercise of Control. United States: W. H. Freeman.

Chaplin, J.P. (2006). Kamus Lengkap Psikologi. Penerjemah: Kartini Kartono. Jakarta: PT. Raja Grafindo.

Dourman, Karel. 2013. Waspada Stroke Usia Muda. Jakarta: Cerdas Sehat.

Hidayat A.A.A. (2008). Riset Keperawatan dan Teknik Penulisan Ilmiah. Jakarta: Salemba Medika.

Ismatika I, \& Soleha U. (2018). Hubungan Self-efficacy Dengan Perilaku Self Care Pasien Pasca Stroke Di Rumah Sakit Islam Surabaya. J Heal Sci, 10(2), 139-48.

Morone G, Paolucci S, \& Iosa M. (2015). In What Daily Activities Do Patients Achieve Independent After Stroke ?. Journal of Stroke and Cerebrovascular Diseases, 24(8).

Prestiana, N. D. I., \& Purbandini, D. (2012). Hubungan antara efikasi diri (self-efficacy) dan stres kerja dengan kejenuhan kerja (burnout) pada perawat IGD dan ICU RSUD Kota Bekasi. SOUL: Jurnal Pemikiran Dan Penelitian Psikologi, 5(2), 1-14.

Riegel, Barbara et al. (2012). A Middle-Range Theory of Self Care of Chronic Illness. Nursing Science, 35(3), 194-204.

Riskesdas. (2013). Riset Kesehatan Dasar 2013. Jakarta: Badan Penelitian dan Pengembangan Kementrian Kesehatan RI.

Rustika, I.M. (2012). Efikasi Diri: Tinjauan Teori Albert Bandura. Buletin Psikologi, 20, 12.Yogyakarta: Fakultas Psikologi Universitas Gadjah Mada. 